\title{
Climate, Extreme Heat, and Electricity Demand in California
}

Norman L. Miller ${ }^{1 *}$, Katharine Hayhoe ${ }^{2}$, Jiming Jin $^{1}$, Maximilian Auffhammer ${ }^{3}$

${ }^{1}$ Earth Sciences Division, Berkeley National Laboratory, University of California, Berkeley, CA 94720

${ }^{2}$ Department of Geosciences, Texas Tech University, Lubbock, TX 79409

${ }^{3}$ Agricultural and Resource Economics Department, University of California, Berkeley

* Atmosphere and Ocean Sciences Group, 1 Cyclotron Road, Berkeley, CA 94720

phone: 510.495.2374, fax: 510.486.5686, email: nlmiller@lbl.gov

Submitted to the Journal of Applied Meteorology and Climatology on 17 April 2006

Revised and resubmitted on 25 October 2006 


\begin{abstract}
Climate projections from three atmosphere-ocean climate models with a range of low to mid-high temperature sensitivity forced by the Intergovernmental Panel for Climate Change SRES higher, middle, and lower emission scenarios indicate that, over the $21^{\text {st }}$ century, extreme heat events for major cities in heavily air-conditioned California will increase rapidly. These increases in temperature extremes are projected to exceed the rate of increase in mean temperature, along with increased variance. Extreme heat is defined here as the 90 percent exceedance probability (T90) of the local warmest summer days under the current climate. The number of extreme heat days in Los Angeles, where T90 is currently $95^{\circ} \mathrm{F}\left(32^{\circ} \mathrm{C}\right)$, may increase from 12 days to as many as 96 days per year by 2100, implying current-day heat wave conditions may last for the entire summer, with earlier onset. Overall, projected increases in extreme heat under the higher Alfi emission scenario by 2070-2099 tend to be 20-30 percent higher than those projected under the lower B1 emission scenario, ranging from approximately double the historical number of days for inland California cities (e.g. Sacramento and Fresno), up to four times for previously temperate coastal cities (e.g. Los Angeles, San Diego). These findings, combined with observed relationships between high temperature and electricity demand for air-conditioned regions, suggest potential shortfalls in transmission and supply during T90 peak electricity demand periods. When the projected extreme heat and peak demand for electricity are mapped onto current availability, maintaining technology and population constant only for demand side calculations, we find the potential for electricity deficits as high as 17 percent. Similar increases in extreme
\end{abstract}


heat days are suggested for other locations across the U.S. southwest, as well as for developing nations with rapidly increasing electricity demands. Electricity response to recent extreme heat events, such as the July 2006 heat wave in California, suggests that peak electricity demand will challenge current supply, as well as future planned supply capacities when population and income growth are taken into account.

\section{INTRODUCTION}

Since 1980, U.S. electricity demand has increased by more than 75 percent, with the largest increases in the residential and commercial sectors for space heating and cooling. As the southwestern U.S. becomes more populated, and extreme heat days become more frequent, electricity demand will continue to rise. A 2005 Government Accounting Office report (GAO 2005) on meeting energy demand in the $21^{\text {st }}$ century states that the U.S. accounts for 5 percent of the world's population, yet consumes 25 percent of the annual energy used worldwide. The GAO report concludes that due to the consumer choices of high consumption, all major fuel sources face environmental, economic, or other constraints or trade-offs in meeting projected demand. Clear and consistent policy is therefore needed to guide energy markets, suppliers, and consumers. The nation's energy infrastructure, its refinery capacity, and electricity line transmission system have not adequately kept up with peak demand, and electricity supply shortfalls have resulted. Electricity generation and transmission deregulation have compounded these problems, as remote transmission and energy gaming have pushed electricity flow up to and beyond the capacity limit, 
often resulting in electricity supply failure. This has already occurred during extreme summer heat events over the last several years, most notably in the summer of 2003, when a system failure resulted in the largest blackout in U.S. history leaving as many as 50 million people without power for several days.

In addition to increasing electricity demand, significant increases in the frequency, intensity, and duration of summertime extreme heat days are also projected due to climate change [Houghton, et al. 2001; Hayhoe et al. 2004; Miller and Hayhoe 2006]. Extreme heat days are defined here as the 10 percent warmest days of the summer, calculated as 1961-1990 warmest days exceeding the 90 percent probability of the summertime daily maximum temperatures (T90) for a given location or region. The correlation between daily mean near-surface air temperature (Ta) and peak electricity demand during such T90 heat extremes suggests the potential for significant temperature-driven increases in future electricity demand for air conditioning [Balzer et al. 1996, Amato et al. 2005, Mendelsohn and Neumann, 1999, Rosenthal and Gruenspecht. 1995; Henley and Peirson, 1998, Cartalis, et al. 2001, Valor et al. 2001]. For example, Colombo et al. [1999] analyzed the frequency of extreme heat and electricity demand for nine Canadian cities using the current climate and a warmer climate based on a doubling in atmospheric greenhouse gas (GHG) emissions. Their study suggests that a $3^{\circ} \mathrm{C}$ increase in the daily maximum temperature would lead to a 7 percent increase in the standard deviation of current peak energy demand during the summer.

California is one of the world's largest economies and a world leader in energy efficiency and demand-side management practices. State-wide, electricity demand 
per capita has remained essentially flat partially due to energy efficiency incentives. However, California's aggregate energy demand is growing rapidly, spurred by the rapid expansion of population (over 36 million) especially in the warm Central Valley region, and an overall increase in the use of air conditioners. The upward trend in aggregate peak demand in California is expected to approach or exceed 67 GW in 2016, which is a 1.35 percent per year increase since 2000 [CEC 2005]. The anticipated population growth underlying these forecasts over the same period is 1.30 percent [CEC 2005], indicating that demand growth is expected to very slightly outpace population growth. During warm summer T90 days in California, the use of air conditioning and other cooling appliances increases electricity load near-linearly with higher temperatures [CEC 2004, Bartholomew et al. 2002]. In 2004, 30 percent of California peak electricity demand was due to residential and commercial air conditioning use alone [CEC 2004].

Extreme heat days during recent summers have triggered energy alerts with brownouts and blackouts. Electricity transmission lines and related infrastructure, along with the restructured energy market, place limits on current expansion of the flow of electricity supply during peak demand periods, and are not expected to be rectified in the near-term [CEC 2004]. During the recent July 2006 heat wave, the warmest year to date since California weather records began in 1895 (NOAA 2006), California minimum temperatures were $8-15^{\circ} \mathrm{F}\left(4.4-8.3^{\circ} \mathrm{C}\right)$ above average. Los Angeles experienced 20 consecutive days at or above $100^{\circ} \mathrm{F}\left(38^{\circ} \mathrm{C}\right)$, and Sacramento experienced 11 consecutive days at or above $110^{\circ} \mathrm{F}\left(43^{\circ} \mathrm{C}\right)$. During this heat wave, there was an all-time single day record electricity demand of $50.3 \mathrm{GW}$ and several 
regions within California were without power from hours to days due to infrastructure failures (e.g. transformers in Northern California were unable to cool properly and caught fire).

One indicator of increased "peakiness" of the electric system is the load factor, which measures the relationship between annual peak demand in GW and consumption in GW hours. If peak demand grows more quickly than the aggregate consumption, then the load factor decreases, highlighting the likelihood of the types of conditions leading to brownouts or even blackouts. The CEC [2005] shows that load factors adjusted for weather have decreased in recent years in California, which is primarily blamed on the increased use of air conditioners.

California's electricity supply reliability problems during periods when demand exceeds the available generating and/or transmitting capacity has already resulted in industries moving to regions with a more dependable supply of electricity. In the future, this issue will continue to plague California, the southwestern U.S., and expanding regions where electricity shortfalls occur. World demand for energy is approximately equivalent to a continuous power consumption of 13 trillion watts (i.e. $13 \mathrm{TW}$ ). With aggressive conservation and energy efficiency, an expected global population of 9 billion accompanied by rapid technology growth is projected to more than double energy demand to $30 \mathrm{TW}$ by 2050 and to more than triple to 46 TW by 2099. Energy shortfalls are already occurring in China and other emerging economies, where the economic expansion has led to a surge in the adoption of household appliances, including air conditioners. If our economies continue on a high-energy consumption trajectory into the future, projected temperature increases 
over the coming century may further strain energy providers, resulting in electricity shortages and negative health and economic impacts.

The next section describes the details of our approach to determining historical and projected extreme heat frequency, intensity, and duration, cooling degrees days, and electricity demand. This is followed by a discussion of the results and evaluation of a potential adaptation strategy, and lastly, the conclusions.

\section{APPROACH}

To quantify the impacts of extreme heat days on peak electricity demand, the historical 1961-1990 maximum temperature exceedance threshold for the 10 percent warmest June through September (JJAS) days (averaging approximately 12 days per year over the historical period) is calculated and referred here as T90. We then calculate the number of projected future JJAS days with maximum temperatures at or above the historical T90 values. T90 values are an important metric used in California energy capacity analyses, and are often described as the 1-in-10 JJAS high temperature days. In addition to the T90 values, we calculate JJAS cooling degree days, which are defined by the National Climatic Data Center (Owenby et al. 2005) as, $\mathrm{CDD}=(\mathrm{Ta}-\mathrm{Tac}) *$ days, where $\mathrm{Ta}$ is the daily mean near-surface air temperature, Tac $=65^{\circ} \mathrm{F}\left(18^{\circ} \mathrm{C}\right)$ is an average daily-mean temperature threshold for human thermal comfort, and days is the number of days with temperatures exceeding Tac. Intensity is simply the difference between Ta and Tac, but it can be further broken down into daytime (maximum) and nighttime (minimum) temperature intensities. Humidity also plays a role in the human thermal comfort threshold; however, 
California is very dry during the summer and therefore this is not a significant factor for this region.

In our analysis of changes in extreme heat we implicitly account for technology and population change through atmosphere-ocean general circulation model (AOGCMs) projections forced by the IPCC Special Report on Emission Scenarios (SRES) [Nakicenovic' et al. 2000]. The SRES scenarios include a range of population increases and accompanying technological and societal changes. However, in the calculation of California's regional energy demand we hold technology and population at today's levels in order to quantify the range of possible outcomes as a perturbation about the historical demand. This perturbation approach has been used in previous impact assessment studies [e.g. IPCC 2001, USGCRP 2000]. It provides a constrained estimate of potential outcomes that can be extrapolated using a range of projected changes in population and technology applied to demand. In our discussion we explore the possibility of such extrapolated scenarios, although technological advancement is difficult, if not impossible, to project beyond about a 10 year timeline due to the large uncertainties pertaining to the rate of discovery, evaluation, and social adaptation of new technologies.

Similar to previous assessments of temperature and extreme heat increases for California [e.g. Hayhoe et al. 2004; Cayan et al. 2006], we use three AOGCMs: DOE/NCAR PCM [Washington et al. 2000], NOAA/GFDL CM2.1 [Delworth et al. 2006], and UKMO HadCM3 [Pope et al. 2000] model. As illustrated by Figure 1, use of three AOGCMs captures the scientific uncertainty inherent in future projections of temperature increases in response to human emissions. PCM lies at the 
lower end while GFDL and HadCM3 fall at the mid to high end of the full IPCC range of 1.5 to $4.5^{\circ} \mathrm{C}$ for a doubling of atmospheric $\mathrm{CO}_{2}$ concentrations (Houghton et al., 2001).

\section{FIGURE 1 HERE}

As also illustrated in Figure 1, even greater uncertainty is introduced by assumptions regarding future emissions from human activities. For that reason, the three AOGCMs are forced by the IPCC SRES high (A1fi; fossil intensive, with rapid technological and economic growth), mid-high (A2; a heterogeneous world, with regionally-oriented development and slower growth), and lower (B1; a convergent world that transitions rapidly to an information rather than material-based economy) emission scenarios, for the period 2000 to 2099. These IPCC SRES scenarios represent the range of non-intervention emissions futures, with projected 2100 atmospheric $\mathrm{CO}_{2}$ concentrations reaching approximately $550 \mathrm{ppm}$ to almost 1000 ppm.

For each of the nine model/scenario combinations used here, projected California-wide temperature increases were first calculated directly from the AOGCM output (Figure 1). This coarse-resolution approach tends to cause a slight cool bias due to the proportion of grid cells near ocean waters and mountainous regions. For that reason, we therefore downscaled maximum and minimum daily temperatures to the individual city level using historical model simulations and the long-term observational weather station records. Downscaled daily temperature 
time-series were generated for five urban centers within the State; San Francisco, Los Angeles, Sacramento, Fresno and San Bernardino/Riverside. Statistical downscaling was accomplished using multiple linear regression equations based on the nearest long-term daily weather station observations for each city. Statistical downscaling procedures have the advantage of being computationally efficient, but as they rely on historical relationships between large-scale climate fields and local variables, partial stationarity over time must be assumed. Statistical downscaling through regression is a common approach that has been well-documented in the literature (Karl et al.1990; Wilby et al. 1998; Huth et al. 2002; Wilby et al. 2002; Wilby and Dawson 2004), with the method used here described in Dettinger et al. (2004). Specifically, observed temperatures for 1976 to 1990 were used to train a set of linear third-order regression equations that transform the large-scale temperature predictors to a local-scale predictand, while preserving the distribution of the observed mean and variance. The resulting model was then verified on the 19611975 period with the downscaled time-series having a near-exact fit to observations. Future projections were then averaged for three time periods (2005-2034, 2035-2064 and 2070-2099) in order to produce climatological near-term, mid-term, and longterm projections of increased temperatures for California on which to base estimates of future shifts in the timing and magnitude of electricity demand.

\section{RESULTS}

In order to determine the likely impacts of climate change under higher and lower emissions scenarios, we calculated projected increases in average daily 
temperature, the number of future days that will exceed the historical T90 threshold, and average JJAS CDD values. These projections are then used as the basis for determining changes in State-wide and urban demand for electricity for cooling under assumptions of present-day population and technology. Lastly, we extrapolate the impacts of upper and lower-bound population growth and technology advances in California to estimate the likely future range of peak electricity demand and also evaluate the potential to mitigate the impact of temperature on electricity shortages through adaptation.

\section{a. Projected Increases in T90 Events}

During the historical period (1961-1990), T90 events occur an average of just over 12 times per year, making up 10 percent of JJAS days. Using the threshold for defining a historical T90 event (see Table 1 for T90 threshold temperatures), we then evaluate the number of days projected to exceed this threshold in the future, both at the State level and for the five urban centers examined here.

As average temperatures rise, we find that the historical T90 threshold will be exceeded more frequently. Moreover, T90 events are expected to be more intense (i.e. hotter), last longer, and occur earlier in the season relative to the 1961-1990 reference period.

For California as a whole, the total number of T90 days doubles relative to a historical mean of 12 days per summer to an average of 23-24 days per summer as early as 2005-2034. By mid-century (2035-2064), we see 27-39 days (B1), 29-47 days (A2), and 32-54 days (A1fi). By the end of the century (2070-2099), the Statewide number of JJAS T90 days are projected to increase an average of 4 times (B1), 
5.5 times (A2), and 6.5 times (A1fi) relative to the historical average (Table 1, Figure 2).

\section{FIGURE 2 HERE}

T90 threshold values for the urban locations vary from a low of $27^{\circ} \mathrm{C}$ for San Francisco up to $40^{\circ} \mathrm{C}$ for Fresno (Table 1). Using city-specific T90 threshold, similar increases in the number of JJAS T90 days are projected for the five urban locations (Table 1). By 2005-2034, in most cities the number of days doubles relative to the historic reference period. By the end of the century, there are projected to be 3.5 to 4 times more T90 days under B1, 5.5 to 6 times more days under A2, and 6 to 7 times more days under the higher A1fi scenario.

As for the State-wide projections, increases for individual urban areas are proportionally larger under the higher emissions scenarios (A1fi and A2) relative to the lower B1. Furthermore, coastal cities (Los Angeles, San Francisco) are projected to see changes of more than 90 T90 days by the end-of-century under the A1fi and A2 scenarios, as compared with slightly lower projections of 70 to 80 T90 days per year for inland areas.

\section{TABLE 1 HERE}




\section{b. Projected Increases in CDD Values}

State-wide annual $\mathrm{CDD}$ values for a $18^{\circ} \mathrm{C}\left(65^{\circ} \mathrm{F}\right)$ mean temperature threshold have an average 400 to $500^{\circ} \mathrm{C}$-days per year for the period 1961-1990. For California as a whole, average $\mathrm{CDD}$ values are projected to increase to $600-1000^{\circ} \mathrm{C}$-days by midcentury. By end-of-century, the difference between emissions scenarios becomes clear, with CDD values for California ranging from $650-1000^{\circ} \mathrm{C}$-days under the lower B1 scenario up to $800-1250^{\circ} \mathrm{C}$-days and $1000-1500^{\circ} \mathrm{C}$-days under the higher A2 and A1fi scenarios, respectively. These increases are double (B1) to triple (A2, A1 fi) the historical values.

Perhaps even more relevant to electricity supply is the average CDD value during a T90 event, when the electric power demand peaks. California currently has a CDD value of approximately $20^{\circ} \mathrm{C}$-days per day during summer heat episodes. For each degree above the base comfort per day $\left({ }^{\circ} \mathrm{C}\right.$-days), an additional amount of energy will be required for cooling.

By mid-century, daily CDD values for T90 days has increased to approximately $100^{\circ} \mathrm{C}$-days. By the end of the century, daily CDD values during T90 events exceed $150^{\circ} \mathrm{C}$-days under most scenarios (Figure 3). Together, the impact of projected increases in T90 day frequencies and duration (with more such events occurring closer together or even consecutively) act to enhance daily average CDD values as well as JJAS totals, likely increasing peak electricity demand.

FIGURE 3 HERE 
At the urban scale, similar increases in CDD values are seen for the five cities (Table 2). Resolving individual urban centers also shows that there are significant inland and coastal differences in the T90 values and the corresponding CDD values, with projected increases being greatest in the southern and inland locations. Additional projected CDD increases for cities further north and south (Crescent City and El Centro, not shown) confirm this north-south gradient of increasing T90 and CDD values. Also in contrast to the T90 analysis, interscenario differences are more evident before the mid-century, with projected increases for 2035-2064 ranging from $50^{\circ} \mathrm{C}$-days per year up to $80^{\circ} \mathrm{C}$-days per year under $\mathrm{B} 1$ and up to $150^{\circ} \mathrm{C}$-days per year under A1fi for the more northerly San Francisco. As the CDD values increase towards the end of the century, even greater increases are seen under the higher A1fi and A2 emission scenarios relative to the lower B1 emission scenario (Table 2). By the end of the century, the projected increase in CDD values under the A2 and A1fi scenarios range from $150^{\circ} \mathrm{C}$-days per year in the north, up to $750^{\circ} \mathrm{C}$-days per year in the south, and are 1.2 to 2.3 times greater than that projected under B1.

\section{TABLE 2 HERE}

\section{c. Projected Increase in Electricity Demand}

Peak electricity demand and temperatures in California are strongly correlated. For temperatures above $28^{\circ} \mathrm{C}\left(82^{\circ} \mathrm{F}\right)$, California peak electricity demand exhibits a linear increase at a rate of $700 \mathrm{MW} /{ }^{\circ} \mathrm{F}$ [DOE 2004, CEC 2002]. In 2004, the 1-in-10 (T90) 
California JJAS peak electricity demand outlook was $57 \mathrm{GW}$, indicating a remaining reserve margin of only 5.5 percent and a Stage I electricity emergency. At electricity demand levels above $57 \mathrm{GW}$, spot markets are used. For State-wide mean daily temperatures above $86^{\circ} \mathrm{F}$, electricity demand exceeds $60 \mathrm{GW}$, and capacity is less than 5 percent, resulting in Stage II electricity emergency response programs being put into effect. When only 3 percent of the reserve margin is available, a Stage III emergency alert is proclaimed, accompanied by rolling blackouts.

Using the above temperature-demand relationship, State-wide JJAS peak electricity demand increases under all projections of future climate change, due to the increased frequency of days warmer than $28^{\circ} \mathrm{C}\left(82^{\circ} \mathrm{F}\right)$. Residential peak electricity demand at mid-century is projected to increase by $2.8-10.0$ percent under the A1fi and A2 scenarios and by 3.4-7.7 percent under the B1 scenario. By the endof-century, this demand will increase by 6.2-19.2 percent under the A1fi and A2 scenarios, and by 4.0-11.2 percent under the B1 scenario. Much of this increased peak demand is projected to occur simultaneously across the state, as extreme heat events are of a regional rather than local nature, raising concerns regarding the reliability and structural stability of the energy grid to supply the needs of all sectors, including industrial, residential, and emergency services.

In our demand analysis we hold the Gross Daily Product (GDP) and aggregate population constant at today's level to illustrate the effect of the increased frequency of extreme heat days on peak electricity demand. Based on this approach, the increases in aggregate demand come from temperature-induced increases in the per capita rate of electricity consumption. CEC (2005) forecasts reflect a growth of 
aggregate peak electricity demand essentially matching population growth. This implies that improvements in "electricity efficiency" of the economy have to exactly offset the increased demand.

Of course, it is not only the increased frequency of extreme heat days that drives up peak demand. Economic growth of California's economy measured by increasing the gross state product is another main determinant of electricity demand. While historically per capita energy consumption has been flat, due to aggressive energy efficiency programs, technological advances will have to offset increases from both of these factors in order to grow electricity supply at the same rate as population growth.

\section{DISCUSSION}

Projected increases in extreme temperatures characterized by a T90 threshold, cooling degree days, and direct estimates of electricity demand all suggest that electricity demand in California is likely to continue to rise over this century. Although California's installed electricity capacity will also continue to grow over time, at its current rates of growth suggest frequent summer electricity shortages may occur as early as 2020. This scenario is particularly more likely for southern California, where the electricity operating reserve has already dropped below the 5 percent reserve margin during multiple hot days in recent years. By the end of this century, all model/scenario combinations indicate an increase in region-wide extreme temperature conditions of a severity associated with electricity shortages under the current configuration of the electric power system and patterns of demand. 
Furthermore, population estimates suggest a large influx along major transportation corridors in the California Central Valley, a region that is already very hot during JJAS, requiring air conditioner use. If we were to impose a doubling and a quadrupling of the population within the Central Valley during this century, then the demand side will also increase proportionally and supply will consequently need to be doubled or quadrupled as well. As mentioned earlier, technological advancement is highly unpredictable; however, there is always the possibility of breakthroughs.

The natural conclusion arising from projections such as these is that electricity production must be significantly increased. However, in future years, meeting California's demand for electricity - including peak power - will most likely require a combination of new supplies, improved transmission and distribution facilities, and further enhancement of the demand-side policies and programs that are already in place. In particular, adaptation to future change through widespread adoption of conservation and passive cooling strategies may have the potential to significantly reduce the projected increase in future electricity demand. By raising the average temperature threshold at which air conditioning is commonly turned on through adaptation strategies such as the use of fans and flow though ventilation, less electricity would be required for cooling under a given temperature regime. This is not unheard-of in California; during the 2000-2001 electricity crises, Californians responded to an imposed electricity efficiency and demand program that resulted in a reduction of approximately $6000 \mathrm{MW}$, representing 10 percent of the peak demand [CEC 2004]. During the summer of 2000, there were 29 days where electricity demand exceeded 40,000 MW. Although the summer of 2001 was as hot as 2000, 
there was a substantial reduction in demand, with only 6 such days occurring. This reduction was due to a combination of price increases and voluntary reduction of electricity use.

Some measure of the adaptive potential for reducing projected increases in CDD and the subsequent rise in residential and commercial electricity demand can be obtained through comparing projected increases in CDD values calculated based on the standard $65^{\circ} \mathrm{F}$ threshold with $\mathrm{CDD}$ values calculated using a higher threshold of $75^{\circ} \mathrm{F}$. Raising the CDD threshold by $10^{\circ} \mathrm{F}$ through more efficient cooling with fans and ventilation would greatly reduce the projected increase in CDD values and related electricity demand, particularly for coastal cities (Figure 4). Using this simplified assumption provides us with a sense of potential savings through adaptation. For San Francisco, raising the CDD threshold to $75^{\circ} \mathrm{F}$ would result in end-of-century $\mathrm{CDD}$ increases of less than $15^{\circ} \mathrm{C}$-day per year, effectively eliminating any increases in projected demand under both the $\mathrm{A} 1 \mathrm{fi} / \mathrm{A} 2$ and $\mathrm{B} 1$ scenarios. Los Angeles shows potential reductions of 40-55 percent in projected CDD increases relative to the $65^{\circ} \mathrm{F}$ threshold, while inland cities (San Bernardino, Sacramento, Fresno) indicate an adaptive capacity ranging from 10-40 percent.

Considering that significantly higher CDD values and related electricity demand result from higher, as compared with lower emission scenarios, and that most affordable near-term options for increasing electricity supply via fossil fuels also involve simultaneous increases in greenhouse gas emissions, these estimates of adaptation potential have important implications for decision-making at the city and state level. 


\section{FIGURE 4 HERE}

\section{SUMMARY AND CONCLUSIONS}

All indicators point to increases in summer electricity demand in California, even when confounding factors such as increased population and market saturation of air conditioning are disregarded. Through calculation of projected increases in extreme heat and electricity demand, we are able to quantify the difference in potential impacts resulting from lower and higher emissions scenarios. Model uncertainties notwithstanding, extreme heat and associated human health risks and electricity demands under the B1 lower emissions scenario are significantly lower than those projected to occur under the A2 and A1fi higher scenarios. Calculations of electricity demand under a range of human comfort levels also highlight the potential for adaptation to play a major role, reducing projected increases in electricity demand by roughly one third for inland cities, and by as much as 95 percent for cooler coastal cities.

Alternative technologies such as solar photovoltaic electricity generation represent an important future technology for this region, with electricity production being proportional to solar radiation and thus closely matching summer peak electricity demand [Borenstein 2005]. Technologies such as these have the potential to reduce the cost associated with increased demand for cooling under a warmer climate without increasing emissions of greenhouse gases that are causing the problem in the first place. 
In conclusion, the influence of climate change on extreme heat and electricity demand in California and other similar air-conditioned regions is likely to challenge current-day providers, spur conservation and adaptation measures, and raise questions regarding the potential for mitigation to reduce projected increases through following a lower emissions pathway worldwide.

\section{ACKNOWLEDGMENTS}

Support for this work provided by the California Energy Commission and by the California Environmental Protection Agency as a contribution to the Governor's Climate Science Report. The findings of this paper do not necessarily represent the views of the funding agencies or the State of California. Work performed for the Department of Energy at Berkeley National Laboratory is under contract DE-AC0376SF0098. 


\section{REFERENCES}

Amato, A., M. Ruth, P. Kirshen and J. Horwitz. 2005. Regional energy demand responses to climate change: Methodology and application to the Commonwealth of Massachusetts. Climatic Change, 71, 175-201.

Batholomew, E.S., R. Van Buskirk, and C. Marnay. 2002. Conservation in California during the summer of 2001. LBNL-51477, $22 \mathrm{pp}$.

Baxter, L. W., and K. Calandri. 1992. Global warming and electricity demand: A study of California. Energy Policy, 20 (3) 233-244.

Belzer, D., M. Scott and R. Sands. 1996. Climate Change Impacts on U.S. Commercial Building Consumption: An Analysis Using Sample Survey Data. Energy Sources, 18, 2.

Borenstein, S. 2005. Valuing the Time-Varying Electricity Production of Solar Photovoltaic Cells. University of California Energy Institute Working Paper 142 (CSEM WP-142).

California Energy Commission (CEC). 2002. 2002-2012 Electricity Outlook Report, P70001-004F, 174pp.

California Energy Commission (CEC). 2004. Integrated Energy Policy Report, California Energy Commission Report 100-04-006CM, 80pp.

Cartalis, C, A. Synodinou, M. Proedrou, A. Tsangrassoulis and M. Santamouris. 2001. Modifications in energy demand in urban areas as a result of climate changes: an assessment for the southeast Mediterranean region. Energy Conv and Mgmt. 42, 16471656.

Colombo, A.F., D. Etkin, and B.W. Karney, 1999: Climatic variability and the frequency of extreme temperature events for nine sites across Canada. J. Climate, 12, 2490-2502.

Delworth, T.L., Broccoli, A.J., Rosati, A., Stouffer, R.J. et al. 2006. GFDL's CM2 global coupled climate models - Part 1 - Formulation and simulation characteristics. J. Climate, 19, 643-674. 
Dettinger, M.D., D.C. Cayan, M.K. Meyer, and A.E. Jeton, 2004: Simulated hydrologic responses to climatic change variations and change in the Merced, Carson, and American River Basin, California 1900-2099. Climatic Change, 62, 283-317.

Department of Energy (DOE). 2004. Technical Support Document: Energy efficiency

program for commercial and industrial equipment: Commercial unitary air conditioners and heat pumps.

Dettinger, M.D., Cayan, D.R., Meyer, M.K., and Jeton, A.E. 2004. Simulated hydrological responses to climate variations and change in the Merced, Carson, and American river basins, Sierra Nevada, California, 1900-2099. Climatic Change 62, 283-317.

Government Accounting Office 2005: Meeting energy demand in the $21^{\text {st }}$ century. GAO-05414T, 34pp. http://www.gao.gov

Hayhoe, K., D. Cayan, C. B. Field, P. C. Frumhoff, E. P. Maurer, N. L. Miller, S. C. Moser, S. H. Schneider, K. Nicholas Cahill, E. E. Cleland, L. Dale, R. Drapek, R. M. Hanemann, L. S. Kalkstein, J. Lenihan, C. K. Lunch, R. P. Neilson, S. C. Sheridan and J. H. Verville. 2004. Emissions pathways, climate change, and impacts on California. Proc. Natl. Acad. Sci., 101, 12422-12427.

Henley, A and J. Peirson. 1998. Residential energy demand and the interaction of price and temperature: British experimental evidence. Energy Economics, 20, 157-171.

Houghton, J.T., et al. (Eds.). 2001. Climate Change 2001: The Scientific Basis. Contribution of Working Group I to the Third Assessment Report of the Intergovernmental Panel on Climate Change. Cambridge University Press, Cambridge, UK and New York, NY.

Mendelsohn, R. and J. Neumann, 1999. The Impact of Climate Change on the United States Economy. Cambridge University Press, Cambridge, UK,

Miller, N.L., K.E. Bashford, and E. Strem: Potential impacts of climate change of California hydrology. J. Amer. Water Resourc. Assoc, 39, 771-784. 2003. 
Miller, N.L. and K. Hayhoe, 2006: Emissions scenario-based analysis of projected extreme heat and energy costs in California, Forum on Risks and Impacts on Society, $86^{\text {th }}$ Annual AMS Meeting, 29 January - 2 February 2006, Atlanta, GA.

Nakicenovic', N., J. Alcamo, G. Davis, B. de Vries, J. Fenhann, S. Gaffin, K. Gregory, A. Grubler, T. Y. Jung, T. Kram, et al. 2000. Intergovernmental Panel on Climate Change Special Report on Emissions Scenarios. Cambridge Univ. Press, Cambridge, U.K.

NOAA 2006: July 2006 Statewide Temperature Ranks, National Climate Data Center, NESDIS http://www.noaanews.gov/stories2006/s2677.htm

Owenby, J., R. Heim, M. Burgin and D. Ezell. 2005. Climatology of the U.S. No. 81 Supplement \# 3, Maps of Annual 1961-1990 Normal Temperature, Precipitation and Degree Days, Online Document Library, http://www.ncdc.noaa.gov/oa/documentlibrary/clim81supp3/clim81.html

Pope, V.D., M. Gallani, P. Rowntree, and R. Stratton. 2000. Climate Dynamics, 16, $123-$ 146.

Rosenthal, D. and H. Gruenspecht. 1995. Effects of global warming on energy use for space heating and cooling in the United States. Energy Journal, 16, 2, 77-96.

Sailor, D. and A. Pavlova. 2003. Air conditioning market saturation and long-term response of residential cooling energy demand to climate change. Energy. 28, 941-951.

Tebaldi, C., K. Hayhoe, J. Arblaster and J. Meehl. 2006. Going to the extremes: An intercomparison of model-simulated historical and future changes in extreme events. Climatic Change, 10.1007/s10584-006-9051-4.

Valor, E., V. Meneu and V. Caselles. 2001. Daily air temperature and electricity load in Spain. J. Appl. Met., 40, 1413-1421.

Wilby, R.L. and C.W. Dawson, (2004): Using the Statistical DownScaling Model (SDSM) Version 3.1 - A decision support tool for the assessment of regional climate change 
impacts. User's Manual. Climate Change Unit, Environment Agency of England and Whales, 67pp.

Wilby, R.L., C.W. Dawson, E. M. Barrow: SDSM - a decision support tool for the assessment of regional climate change impacts. Environmental Modelling and Software 17(2): 145-157 (2002)

Washington, W. M., J. W. Weatherly, G. A Meehl, A. J. Semtner, T. W. Bettge, A. P. Craig, W. G. Strand, J. Arblaster, V. B. Wayland, R. James, and Y. Zhang. 2000. Parallel climate model (PCM) control and $1 \%$ per year $\mathrm{CO} 2$ simulations with a $2 / 3$ degree ocean model and $27 \mathrm{~km}$ dynamical sea ice model. Climate Dynamics, 16, 755-774. 


\begin{tabular}{|l|c|c|c|c|c|}
\hline & T90 threshold $\left({ }^{\circ} \mathrm{C}\right)$ & Scenario & \multicolumn{3}{|c|}{ No. of days exceeding T90 threshold } \\
\hline \multirow{2}{*}{ State-wide } & $1961-1990$ & & $2005-2034$ & $2035-2064$ & $2070-2099$ \\
& 35 & A1fi & $19-34$ & $32-66$ & $69-88$ \\
& & A2 & $18-30$ & $29-47$ & $53-76$ \\
& & B1 & $21-26$ & $27-39$ & $39-52$ \\
\hline San Francisco & 27 & A1fi & 20 & $32-46$ & $70-94$ \\
& & A2 & $13-28$ & $20-48$ & $40-91$ \\
& & B1 & $17-23$ & $23-35$ & $37-49$ \\
\hline Los Angeles & 33 & A1fi & 24 & $34-50$ & $63-93$ \\
& & A2 & $16-24$ & $23-48$ & $39-98$ \\
& & B1 & $19-24$ & $27-36$ & $38-45$ \\
\hline Sacramento & \multirow{2}{*}{38} & A1fi & 20 & $33-46$ & $70-78$ \\
& & A2 & $15-36$ & $25-49$ & $47-89$ \\
& & B1 & $17-23$ & $26-42$ & $40-52$ \\
\hline San Bernardino & \multirow{2}{*}{40} & A1fi & $21-23$ & $31-46$ & $63-78$ \\
& & A2 & $13-27$ & $20-46$ & $36-87$ \\
& & B1 & $20-27$ & $26-36$ & $36-45$ \\
\hline Fresno & 40 & A1fi & $19-21$ & $33-45$ & $69-75$ \\
& & A2 & $15-35$ & $25-51$ & $46-93$ \\
& & B1 & $16-27$ & $26-42$ & $40-52$ \\
\hline
\end{tabular}

Table 1. T90 threshold values (in degrees Celsius, determined such that an average of 12 days per year exceed the T90 threshold during the period 1961-1990), and projected increased number of days exceeding the 1961-1990 T90 threshold for nearterm (2005-2034), mid-century (2035-2064) and end-of-century (2070-2099) periods. Values shown are the range given by HadCM3, GFDL and PCM model simulations for the A1fi (higher), A2 (mid-high) and B1 (lower) emissions scenarios. 


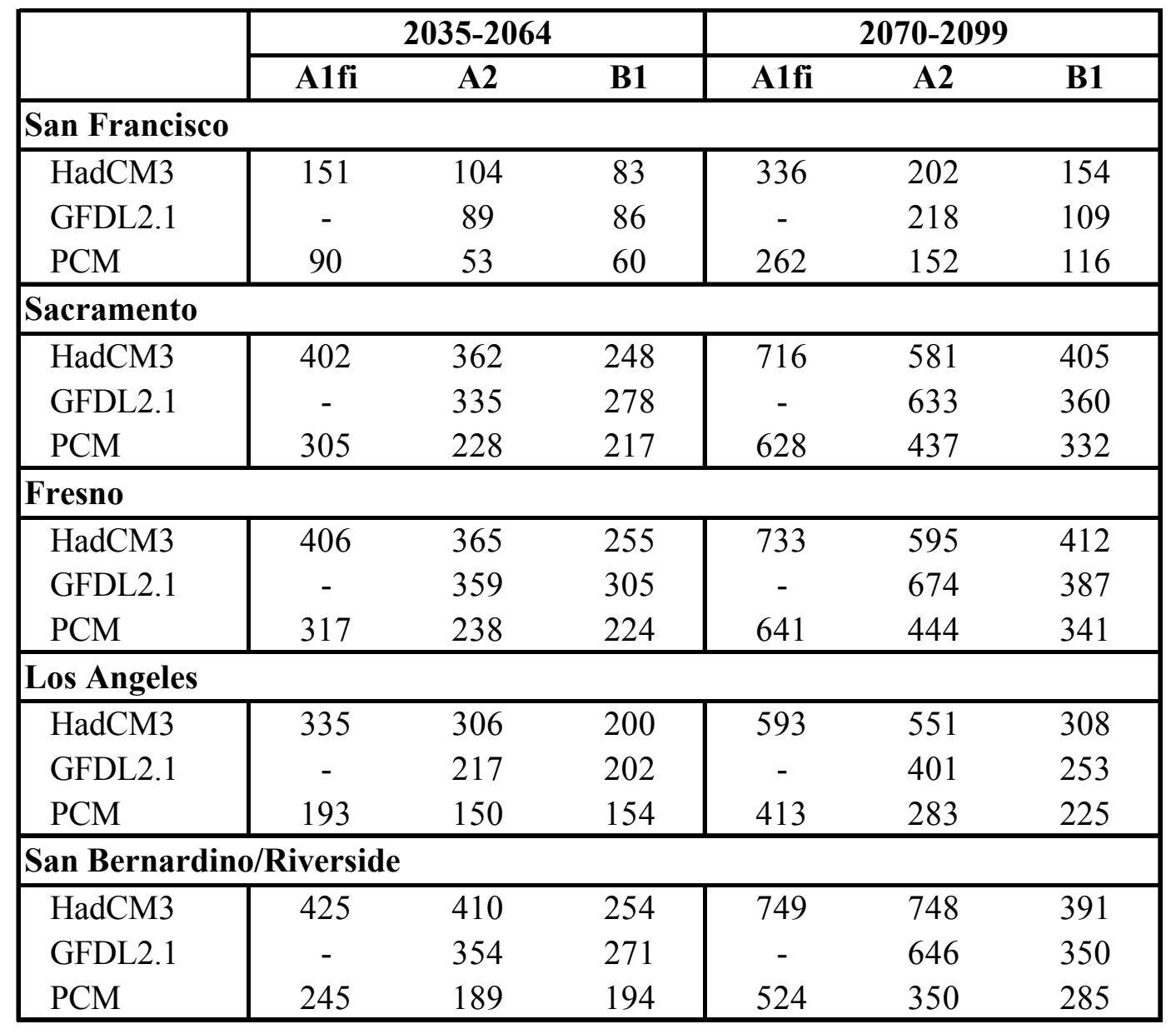

Table 2. Projected change in annual Cooling Degree Days (CDD) for a $65^{\circ} \mathrm{F}$ threshold for 2035-2064 and 2070-2099 relative to 1961-1990 values. Results are shown for the SRES A1fi (higher), A2 (mid-high) and B1 (lower) emission scenarios as simulated by the HadCM3, GFDL2.1 and PCM models for five California cities, listed from north to south. 


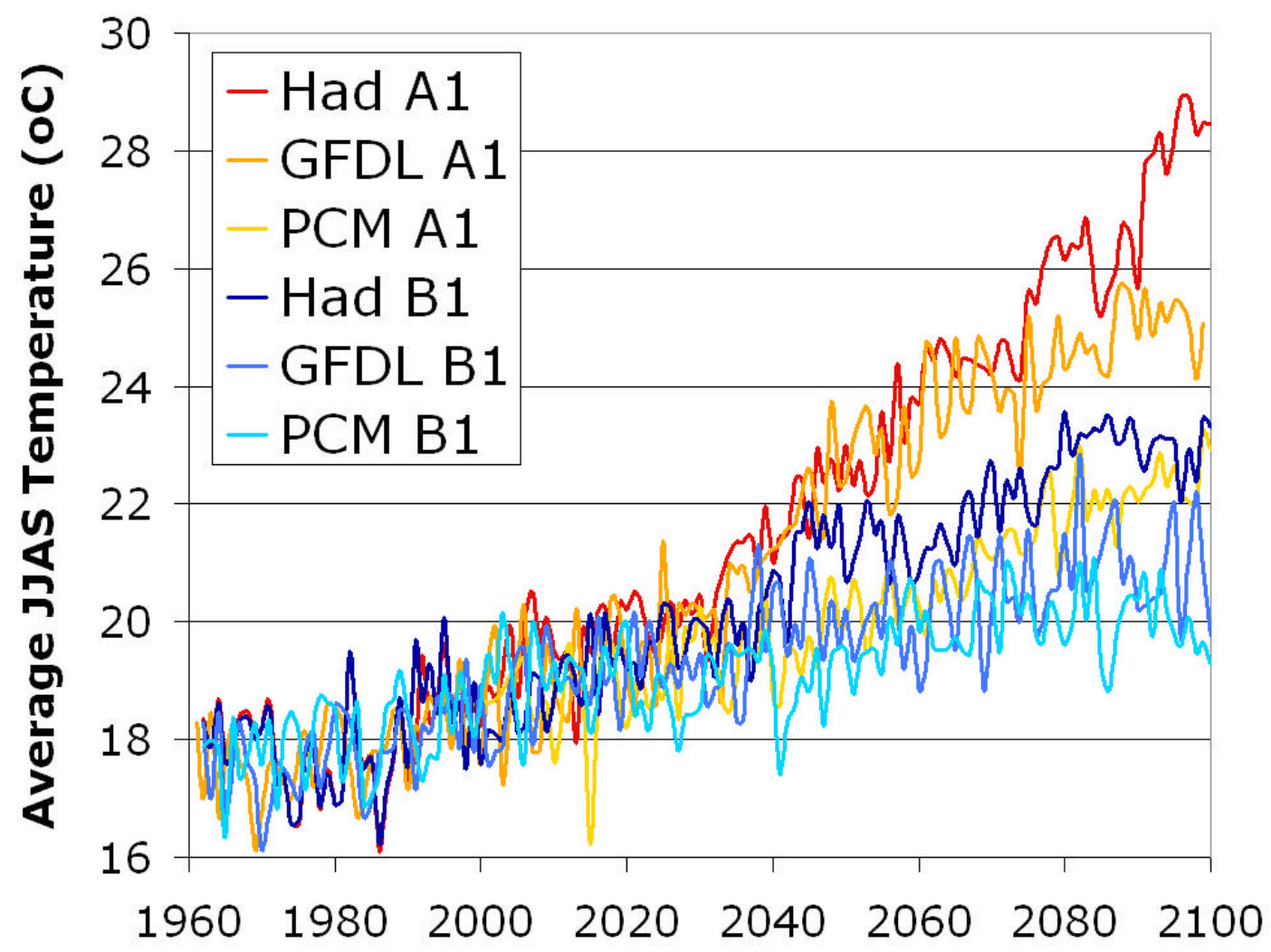

Figure 1. For each scenario in California, HadCM3 has the highest temperature change; GFDL is next, and PCM is last. 


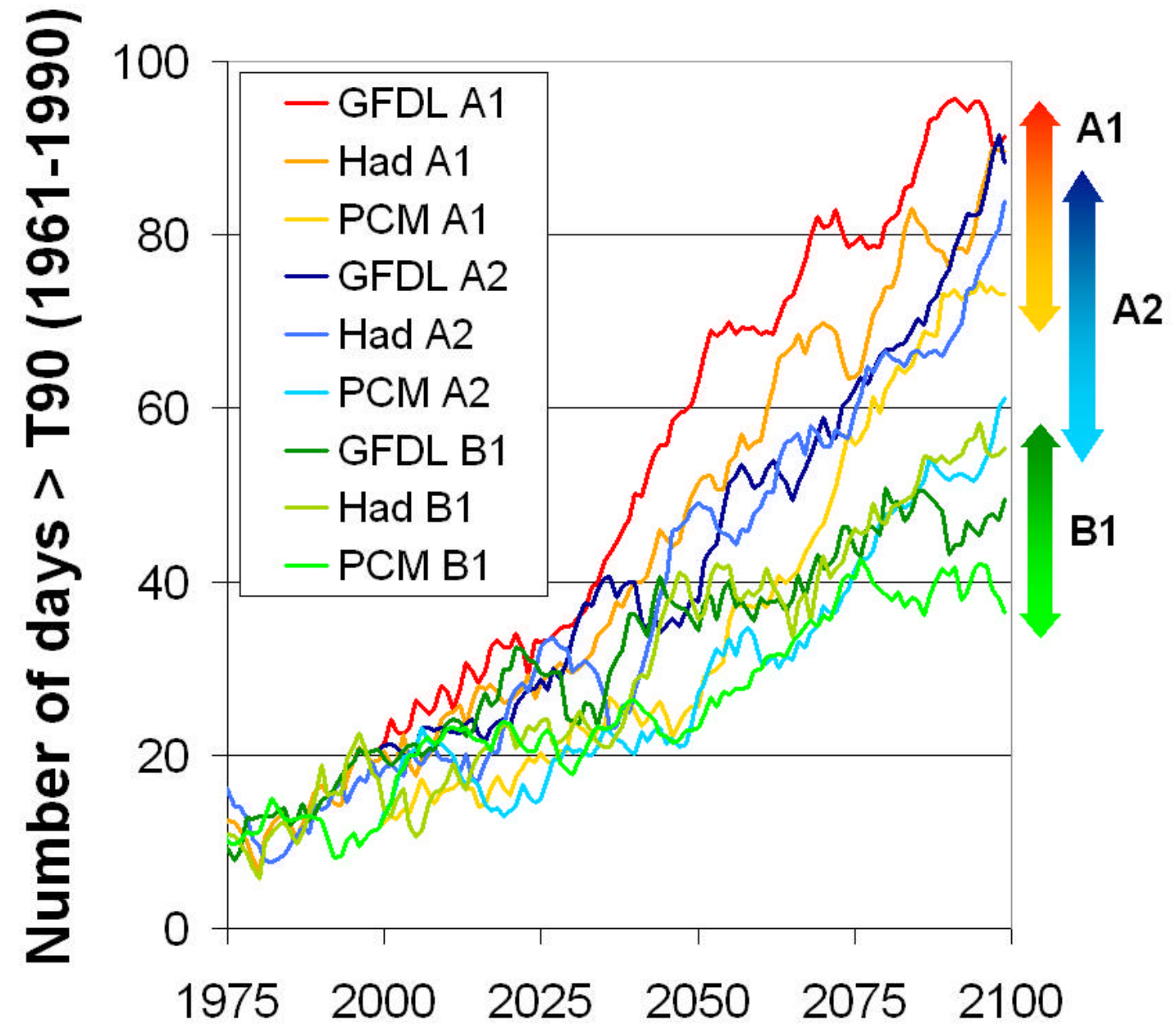

Figure 2. California-wide projected average number of JJAS T90 days per year from 1975 to 2100 . Year-to-year variations have been smoothed using a 10-year running mean to show long-term trends. Projected values are shown for the HadCM3, GFDL and PCM models. Shaded arrows indicate the end-of-century range for simulations corresponding to the A1fi (higher, red/orange), A2 (mid-high, blue) and B1 (lower, green) emission scenarios. 

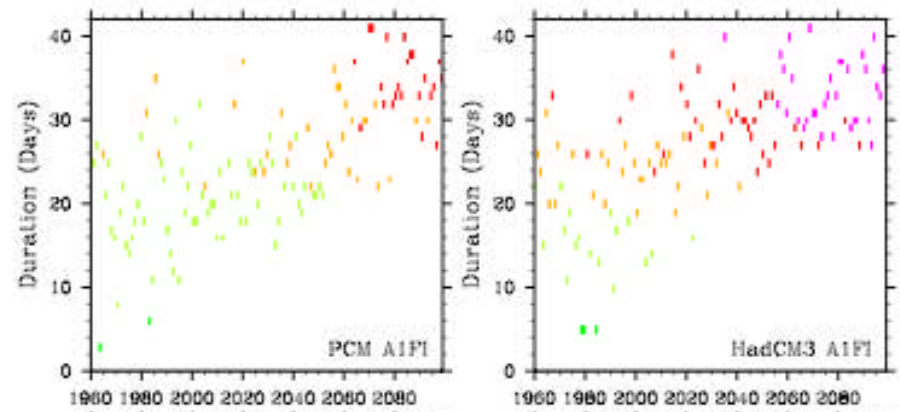

GFDL A1fi output was not available
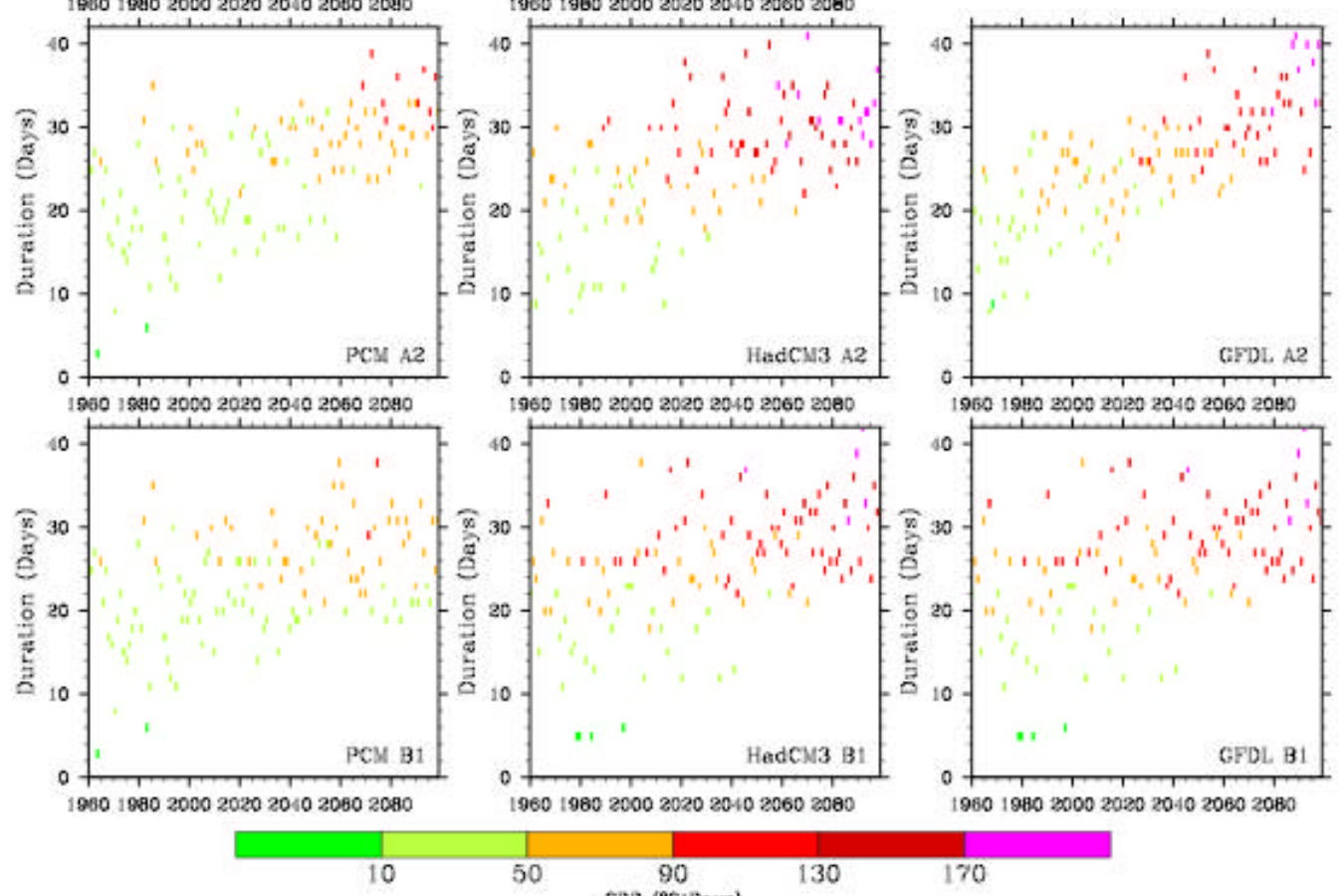

1960198020002020204020602080

1960198020002020204020602080

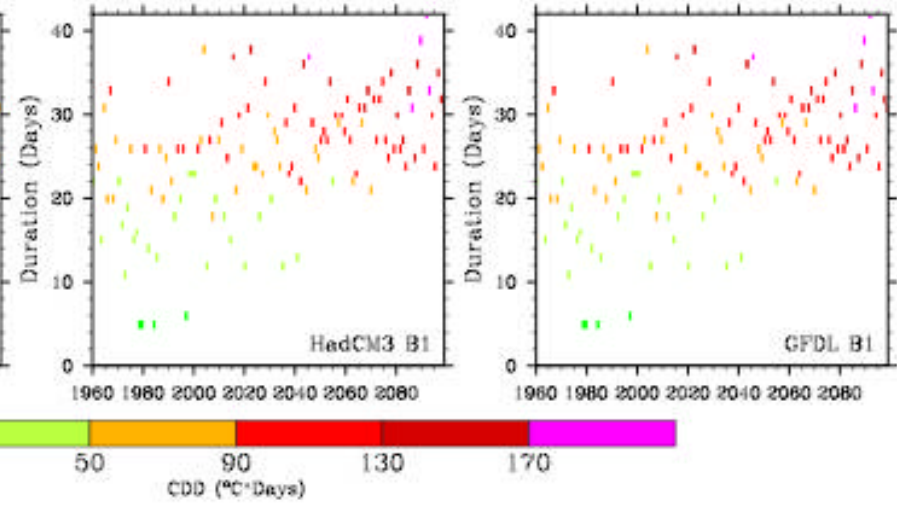

Figure 3. California-wide duration and intensity for JJAS T90 from 1960 to 2100 for

(A) PCM/A1fi, (B) HadCM3/A1fi, (C) PCM/A2, (D) HadCM3/A2, (E) GFDL/A2,

(F) PCM/B1, (G) HadCM3/B1, and (H) GFDL/B1. GFDL A1fi was not available. 


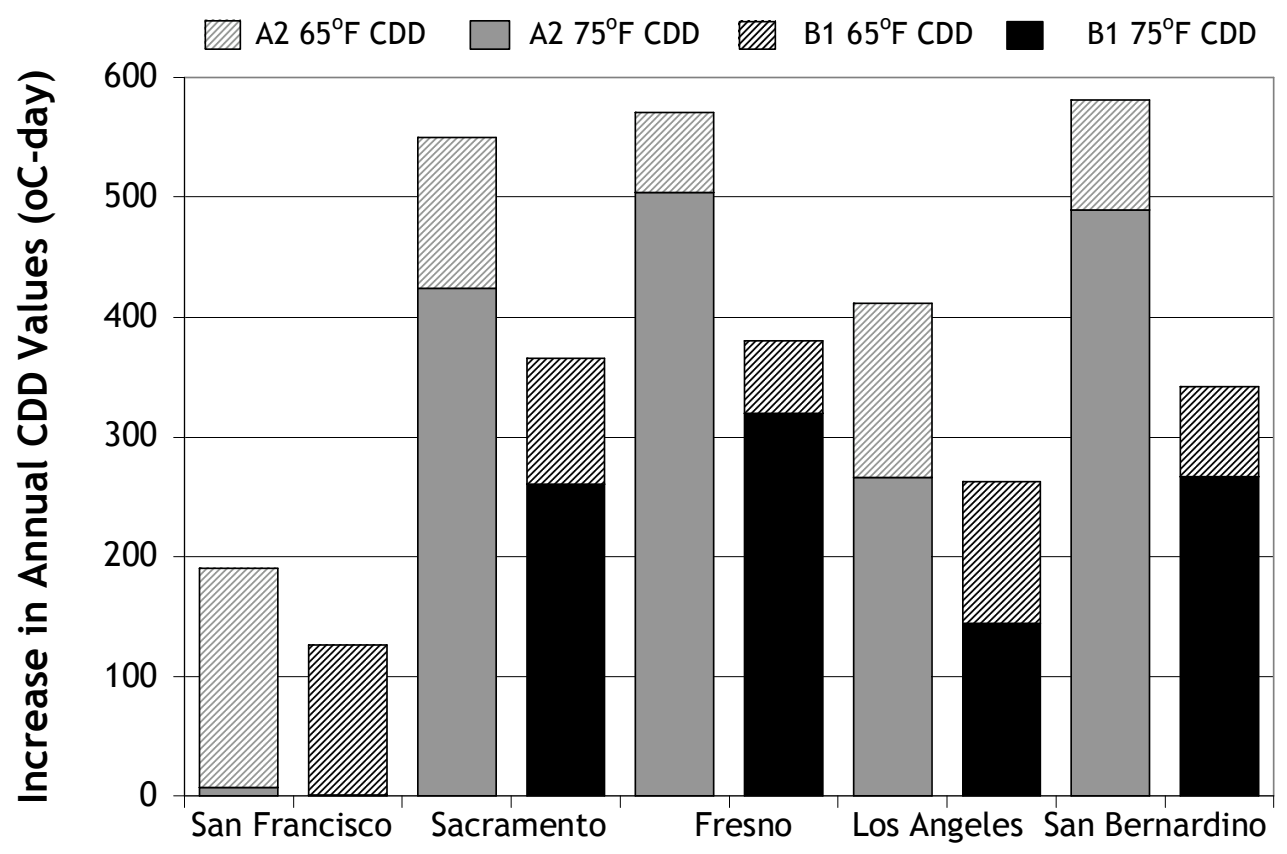

Figure 4. Projected increase in annual CDD for a $65^{\circ} \mathrm{F}$ (solid) vs. a $75^{\circ} \mathrm{F}$ (dotted) average temperature threshold for 2070-2099 relative to 1961-1990. Results shown are the averaged projections from the HadCM3, GFDL2.1 and PCM models for the SRES A2 (mid-high, orange) and B1 (lower, yellow) emission scenarios for five California cities. Comparison of the projected change based on a higher vs. a lower threshold value for CDD calculation illustrates the adaptation potential for mitigating projected future energy demand, which appears to be greater for coastal cities (San Francisco, Los Angeles) and less for inland areas (Sacramento, Fresno, San Bernardino). 